\title{
Walk this way: pedestrian accessibility and equity in Barranquilla and Soledad, Colombia
}

\begin{abstract}
As a transport mode available to everyone and most abled-bodied urban residents, walking is, potentially, the most equitable mode of transport. Walking brings several benefits to inhabitants among money savings and health improvement. Unfortunately, despite its benefits, walking is not a priority in the urban planning agenda of some cities, especially in the Global South. Walkability conditions in some areas of these cities are not particularly friendly for pedestrians, which discourage walking trips and promotes inequities across inhabitants. Evidence supporting inequalities in the provision of adequate conditions for the use of active transport in the Global South cities remain scarce. This paper aims to contribute to filling this gap by first proposing a framework to link pedestrian accessibility with walkability measures. Specifically, we use a macro-scale measure of pedestrian accessibility and a meso-scale measure of walkability to compare walking conditions on different zones in Barranquilla and Soledad, Colombia. After comparing both measures, we found that low-income zones have higher walkability indexes but present lower potential pedestrian accessibility. In contrast, the highest potential pedestrian accessibilities were located in high and medium-income zones, where people rely more on private transport modes. This imbalance regarding supply and demand conditions for walking trips suggest that unfortunately, zones with the highest potential of being walkable are the ones that face more barriers to walk. Then, adequate planning policies when implemented in the right locations could promote higher use of walking and have the potential to reduce current inequalities in pedestrian infrastructure provision.
\end{abstract}

Keywords: Potential pedestrian accessibility, walkability index, walking, pedestrians, equity, Barranquilla, Soledad

\section{Introduction}

Active transport promotion has gained relevance during the last decade in both transport research and practice, partly as a consequence of rising congestion levels, pollution and traffic fatalities caused by intensive use at the global scale of motorised transport modes (Maibach et al., 2009). Such an interest in active travel has been witnessed across cities in the global north and south, with examples of progressive shifts towards walking and cycling from Rwanda to the Netherlands. The shift to active transport modes implies positive effects for both walkers and society, contributing to reduce negative environmental and health externalities while generating individual and societal benefits (Reyer et al., 2014; Sallis et al., 2004).

Despite its benefits and social relevance, walking has not been a priority in urban planning agendas of most cities, particularly in the Global South. In Latin America, historically high investments in urban highways to promote private motorised transport and in public transport, which have been often promoted as "the" primary solution for the mobility of the urban poor, contrast with lack of public investment in pedestrian spaces and bicycle infrastructure. Furthermore, car-oriented and segregating urban planning and regulations have increased urban sprawl and socio-spatial inequalities, resulting in a marginalisation of lower-income residents pushed towards the urban peripheries (Oviedo \& Dávila, 2016) and has locked development in motorised-dependent trajectories at the cost of more active transport modes, mainly walking and cycling (Herrmann-Lunecke et al., 2020).

Walkability conditions in some areas of Latin American cities, especially in low-income neighbourhoods, are not particularly friendly for pedestrians, promoting inequities across inhabitants and discouraging walking trips (Larrañaga et al., 2014). Despite a disproportionate high dependency on walking for their daily mobility, lowincome pedestrians face conditions that range from total lack of infrastructure and high exposure to traffic-related and environmental risks to barriers on pavements that affect comfort, safety, and attractiveness conditions of walkability (Larranaga et al., 2019; Oviedo \& Titheridge, 2016). In many of the poorest neighbourhoods across the global south, pedestrian spaces do not exist, are unpaved, undersized, without green areas, poor lighting, or occupied by parked cars (Herrmann-Lunecke \& Mora, 2018). Evidence supporting inequalities in the provision of adequate conditions for the use of active transport in Latin American cities remain scarce. This paper aims to address this gap by, first, proposing a framework linking pedestrian accessibility with walkability measures. Second, we interrogate such measures to compare walking conditions on different zones using Barranquilla and Soledad, Colombia as case study. Third, we critically examine equity gaps for walking throughout the city, drawing insights for policy and practice in similar contexts. 
Implementing policies to develop walkable neighbourhoods to encourage walking trips (Frank et al., 2010; Frank \& Bernanke, 2007) is associated with positive impacts for urban societies and contribute to improving quality of life. Furthermore, research has suggested that a good walking environment with well-designed infrastructure can reduce transport disadvantage for groups such as elderly and disabled populations (Mackett et al., 2008). Developing walkable neighbourhoods involves providing adequate built environment (BE) characteristics that promote walking instead of using motorised transport modes to complete individual trips (Christiansen, Madsen, Schipperijn, Ersbøll, \& Troelsen, 2014; Larranaga, Cybis, Arellana, Rizzi, \& Strambi, 2016).

The concept of accessibility in its different scales is at the core of walkability. Accessibility is intrinsically related to the role of the land-use and transport systems in society, which will give individuals or groups of individuals the opportunity to participate in activities in different locations (Geurs \& van Wee, 2004). In this regard, to provide the appropriate conditions of the built environment to encourage walkability can be placed at the centre of policy and decision-making in urban planning. An adequate land use mix is vital to enhance the use of active transport (Saelens et al., 2003). Considering that the location of activities plays an essential role in people's mobility and their accessibility to specific opportunities (Choi et al., 2019), land-use distribution can directly influence the desire and ability of individuals and social groups to reach locations and perform activities that ultimately shape travel demand patterns (Ortúzar \& Willumsen, 2011). We part from the notion that walking plays an essential role in enabling access to the city, reducing spatial and social inequalities and either bridging or widening gaps across social groups and geographies.

With this notion in mind, the remainder of this paper is as follows. The second section discusses some relevant literature. The third section presents the conceptual framework to compare walking conditions of different zones, and to evaluate equity. This section also describes the study area. The fourth section contains the data analyses and some discussion about inequities regarding transport and infrastructure provision throughout the city. Finally, the fifth section concludes and recommends further research steps.

\section{Literature review}

The literature recognises the influence of BE characteristics on walkability (Adams et al., 2014; Arellana, Saltarín, Larrañaga, Alvarez, \& Henao, 2020). The BE generally refers to the combination of land use characteristics, transport systems, physical infrastructure, and urban design (Tian \& Ewing, 2017), encompassing many components of accessibility (Geurs \& van Wee, 2004). The multidimensionality of the BE was firstly recognised on the famous concept of the 3Ds (Cervero \& Kockelman, 1997), which characterise BE with measures such as density, diversity, and design.

Other categorisations have been adopted in the literature to describe the BE characteristics. For example, the London Planning Advisory Committee (Gardner et al., 1996) grouped BE characteristics into five components, developing the 5Cs concept: Connected, Comfortable, Convenient, Convivial, and Conspicuous. Later, Moura et al. (2017) added two new dimensions to this 5Cs concept: Coexistence and Commitment. Alfonzo (2005) grouped $\mathrm{BE}$ variables according to the hierarchy of walking needs. She defined five levels of needs, considering the walking decision-making process. These needs stand from the most basic need, feasibility (related to personal limits), and extend to higher-order needs (related to urban form) that include accessibility, safety, comfort, and pleasurably.

The literature has suggested a close link between walking and density, understood as the intensity of population or households in a given area. The higher the density, the higher the walking trips (Larrañaga et al., 2014). Diversity refers to land-use mix patterns, which can also serve as drivers for walking trips. When land uses are similar within a zone, they induce people to use motorised transport modes to reach opportunities outside the area (Frank et al., 2010). In contrast, diverse land use patterns promote walking trips in a zone. Finally, the design dimension is related to street connectivity, road network density, and sidewalk networks (Sallis et al., 2006). Several studies report that urban form and street connectivity have a direct influence on walking trips (Frank et al., 2007; Sallis et al., 2006; Timperio et al., 2006).

Regardless of the categorisation adopted, evidence supports policies to promote changes in the BE to encourage walking trips. Ewing and Cervero (2010) and Saelens and Handy (2008) confirmed the existence of a positive relationship between walking and BE characteristics. These reviews concluded that walking is most strongly related to measures of land use diversity, intersection density, and the number of destinations within walking distance. Contrary to expectations, the authors found population and job densities to be only weakly associated 
with travel behaviour. The above reviews suggest that urban planning decisions regarding the location of activities and the design of the BE characteristics shape the willingness to walk in certain areas (i.e. walkability).

Walkability refers to those BE characteristics that make friendly the presence of people walking, living, shopping, visiting, enjoying, or spending time in the street space (Arellana et al., 2020). Many walkability metrics have been developed globally, considering diverse scales of measurement, and different components in their formulation. Frank et al. ( Frank et al., 2010) developed the most popular walkability index (WI), which includes meso-scale variables such as net residential density, retail floor area ratio, land use mix, and intersection density. The literature recognises such walkability index (Frank et al., 2010) as a good measure to evaluate how walkable an urban area is (Adams et al., 2014; Bödeker, 2018; Clark et al., 2014; Ellis et al., 2016).

The health, environmental, and social benefits of walking largely justify the promotion of walkability. Walkable zones are associated with higher physical activity (Adams et al., 2015; Braun et al., 2016; de Sa \& Ardern, 2014), which is desirable to overcome health problems that have become a significant concern in the last years due to inactivity (Adams et al., 2014, 2015). Along with cycling, walking is accepted as a sustainable transport mode, that not only reduces congestion but also is convenient for short distances and environmentally friendly, in terms of air and noise pollution (Gutiérrez et al., 2020; Ortúzar, 2019). Regarding social benefits, walking has both social and recreational value, and also is the most equitable mode of transport (Forsyth \& Southworth, 2008). It promotes individual social interaction with the community but also is socially equitable because is available to a majority of the population, including children, seniors, and people belonging to different socioeconomic groups (Southworth, 2005). This transport mode also has the potentiality to reduce social exclusion by providing access to some activities to those otherwise socially excluded people (Boyce, 2010; Lucas, 2019; Pucci \& Vecchio, 2019).

As a mode available to all income groups and most abled-bodied urban residents, walking is, actually, the most equitable transport mode (Forsyth \& Southworth, 2008). However, there are some social and spatial equality issues associated with active transport that have received little attention in the literature and are inconsistently applied in practice (Lee et al., 2017). Evidence supporting inequalities in the provision of adequate conditions for walking is scarce, especially in the Global South context, where low-income people and other transport disadvantaged groups mostly rely on this mode of transport to access their opportunities. Numerous studies support the relevance of walking as the most important transport mode in this region, especially to perform short distance trips (Guzman et al., 2020) and diverse activities ranging from work, care-related and other discretionary activities. Furthermore, pedestrian infrastructure have the potential to provide access for all, including women and other underrepresented groups that disproportionately perform a high number of walking trips walking (Sagaris \& Tiznado-Aitken, 2020).

In addition, urban development plans do not usually incorporate equity concepts regarding active transport. In this regard, Pereira et al. (2017) highlight the need to incorporate equality and distributional effect considerations when evaluating investments in infrastructure. Notably, walking infrastructure investments and urban planning policies should consider the extent to which they help reducing inequalities in transport accessibility, particularly how they improve the accessibility of disadvantaged populations. Lucas \& Jones (Lucas \& Jones, 2012) reported that vulnerable populations such as children, older people, disabled people, and low-income population, are more prone to experience social exclusion. The systematic reduction of the ability to reach opportunities of individuals mediated by intersecting differentiations of gender, age, ethnicity and class among other social identities, reflects inequities in transport planning that reinforce already marked cycles of segregation and exclusion (Levy, 2013). Currie et al. (2010) suggest that overall, disadvantaged groups in contexts such as Australia are more vulnerable to social exclusion by means of such intersecting social identities rather than because of transport planning problems. The above is not necessarily true in global south contexts, where high-income is strongly related to vehicle ownership, experience higher access to different transport alternatives, and could face fewer barriers for walkability (Larranaga et al., 2019) due to better BE characteristics near their households. In the same context, lower income citizens, women, elderly and children face a combination of reduced access to private motorised transport, long travel distances and increased violence in public space that constrain further their accessibility and mobility (Yañez-Pagans et al., 2018). Spatial inequalities regarding walkability conditions can also be found in these cities. Inhabitants travelling from low-income to high-income zones usually experience higher walkability at their destination (Herrmann-Lunecke et al., 2020).

Social, spatial and transport-related inequalities in the Global South also translate in inequalities in terms of safety, security, and micro-scale walkability conditions. For example, vulnerable road users (i.e. pedestrians, cyclists, motorcycle users) in Colombia contribute to about $85 \%$ of the total deaths and injuries in traffic accidents (Instituto Nacional de Medicina Legal y Ciencias Forenses, 2019). Security is another primary concern when walking in 
Global South cities (Arellana et al., 2020), especially in low-income neighbourhoods (Oviedo \& Titheridge, 2016). Herrmann-Lunecke et al. ( 2020) and Orozco-Fontalvo et al. (2019) report that women suffer sexual harassment while walking or using public transport services, considering two different Latin American examples.

Building on such inequalities and their manifestation at different scales, we propose a combination of a meso-scale measure of walkability and a macro-scale measure of pedestrian accessibility to identify inequalities in access to opportunities for pedestrians of socioeconomic groups, identifying socially and spatially differentiated features of the built environment's characteristics for walking.

\section{Methodology}

This section presents first, a conceptual framework involving pedestrian accessibility measures to allow comparing walking conditions on different zones in a city. Second, it describes the study area used to test the proposed conceptual framework.

\subsection{Conceptual framework}

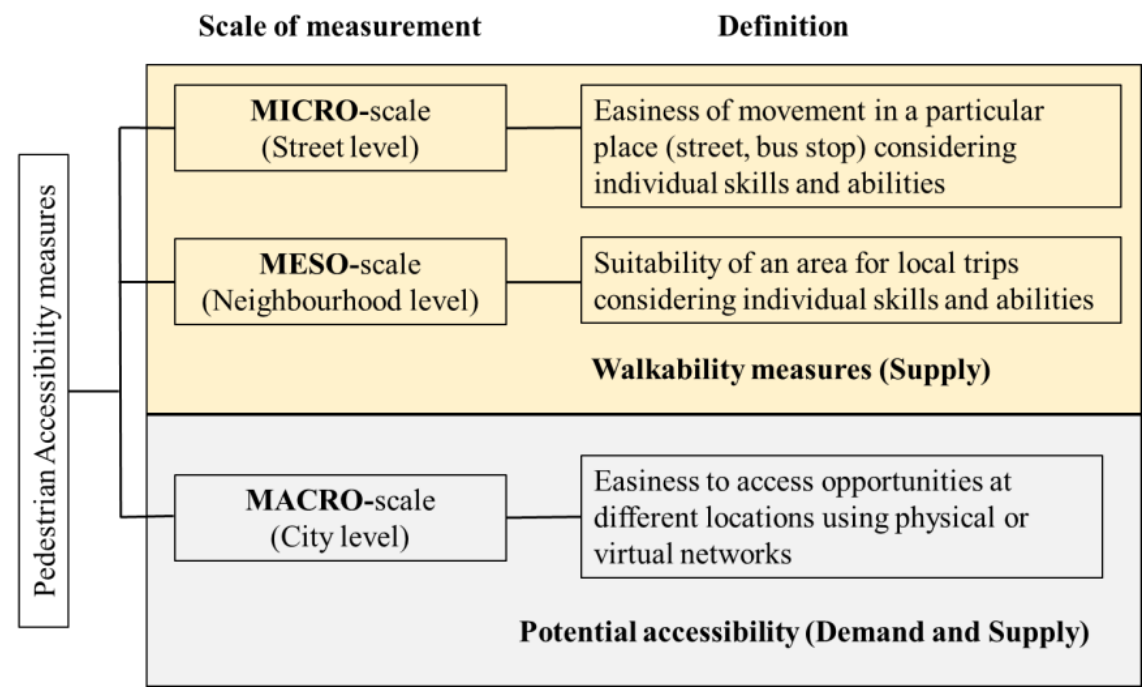

Figure 1. Conceptual framework of accessibility measures

Figure 1 presents the conceptual framework linking pedestrian accessibility measures at different scales. First, micro-scale measures refer to the individual skills and physical ability to manoeuvre through the transport system in a particular place (e.g. boarding a bus, crossing the road, walking in a sidewalk). This category includes walkability measures considering micro-scale variables that allow capturing street-level characteristics such as the slope of the streets, the quality of the sidewalks, and other pedestrian infrastructure (Kim et al., 2014). Some authors have highlighted the importance of considering micro-scale variables in the assessment of walkability (Larranaga et al., 2016, 2019), especially in Global South contexts. This scale of measurement allows identifying different visual, mobility, and other barriers that people with or without mobility impairments can face while walking in a place. Unfortunately, we decided not to include a detailed micro-scale assessment of all street network because of lack of data and its complexity in terms of resources required for data collection. However, considering its relevance, we randomly selected at least one road section per zone and performed a qualitative assessment of its micro-level characteristics. Although this approach is not representative of the entire network in each zone, at least is indicative of the walkability conditions at the micro-scale that would be expected in different parts of the city.

Second, meso-scale measures evaluate the suitability of individuals to make their trips within a given area. Walkability measures considering meso-scale variables are more popular than those using micro-scale variables. Meso-scale walkability measures are commonly used to identify if a neighbourhood is walkable (Adams et al., 2015; Arellana et al., 2020; Bödeker, 2018; Braun et al., 2016; de Sa \& Ardern, 2014) and includes aspects of connectivity, attractivity, and route directness. The most popular walkability measure in this category was 
developed by Frank et al. ( Frank et al., 2010), which includes meso-scale variables such as net residential density, retail floor area ratio, land use mix, and intersection density.

In this paper, we use a modified version of the Frank et al. ( Frank et al., 2010) walkability formulation to represent meso-scale measures. The formulation consists of a composite index considering BE factors to measure the relationship between the physical environment and walking. Specifically, the index considers normalised $Z$-scores of the intersection density, land use entropy score, population density, and commercial density, according to equation (1).

$$
W I=\left(2 \times z_{\text {intersection density }}\right)+z_{\text {population density }}+z_{\text {commercial floor area density }}+z_{\text {land use entropy score }}
$$

(Equation 1)

Intersection density includes all intersections with three or more legs. The ratio of the population and the total area of the Traffic Analysis Zones (TAZ) in squared meters coming from the household mobility survey defined the population density. The commercial floor area in squared meters divided by the total area of the TAZ defined the commercial density. Finally, an land use entropy score was computed by adding up the proportion of land use (e.g. residential, retail, entertainment and institutional) multiplied by the natural logarithm of this proportion and dividing the entire sum by the natural logarithm of land use categories in the zone. This represents land-use diversity. Higher land use entropy scores should encourage pedestrians to walk and suggest that they can reach their opportunities more quickly. In summary, a higher WI index implies that BE characteristics in the zone promote more walking trips than other areas with lower WI index.

Third, macro-scale measures define the ease with which individuals access to opportunities at different locations using physical diginetworks. Unlike the other categories that mainly focus on the pedestrian transport supply and walking facilities, the macro-scale category captures the interaction between walking demand and supply. The macro-scale measure evaluates the potential pedestrian accessibility to opportunities by considering transport networks that enable the movement of people and goods, BE characteristics (e.g. land uses), and the location and quantity of opportunities. In other words, the macro-scale accessibility measures allow quantifying the potential access to opportunities from a given origin to all destinations using a given transport mode; in this case, the walking mode.

In this paper, we use the potential accessibility definition of Geurs \& van Wee (2004) to represent macro-scale measures. The measure evaluates the access to shop, job, study, and institutional opportunities from a zone $i$ to all the other zones $j$ by walking, according to equation (2).

$$
A_{i}=\sum_{j=1}^{n} O_{j} e^{\left(-\beta_{i} c_{i j}\right)}
$$

where $A_{i}$ represents the potential pedestrian accessibility from origin zone $i, O_{j}$ refers to the opportunities available in destination zone $j$ and can be accessed from zone $i, C_{i j}$ represents the generalised cost for walking between $i$ and $j$ zone. Finally, $\beta_{i}$ is a calibration parameter associated with the easiness of walking between $i$ and $j$. This expression allows to assess the effects of household and activities locations on accessibility to jobs, study and shop places within the pedestrians by transforming walking travel time into a measurable number of reachable opportunities. Such measures of potential accessibility have been deployed across Latin America in various contexts since the early 2010 s, serving as a tested means for addressing macro-scale accessibility and inequalities (Bocarejo \& Oviedo, 2012; Vecchio et al., 2020).

For this macro-scale evaluation, we included only complete trips by walking. We aimed to isolate walking as the primary transport mode for proximity trips, considering that walking trips represent about one-third of all trips in Barranquilla. Even though it would be interesting to consider the walking legs of public transport trips, including these trips, may slightly distort the accessibility results to specific destinations due to the efficiency or inefficiency of the bus system. Moreover, its inclusion could increase accessibility levels for low-income groups who cannot even afford the public transport service.

Finally, we also developed an equality analysis which is important because pedestrian infrastructure and opportunities location it is not the same, nor is it located uniformly in the study area. To compare the distribution of accessibility levels among the population (horizontal equality) and different socioeconomic levels (vertical 
equality), we propose to use Lorenz curves and Gini indexes ( Guzman, Oviedo, \& Rivera, 2017; Lucas, van Wee, \& Maat, 2016).

For the analysis, we used information from the latest household Origin Destination survey issued as a part of the Master Mobility Plan for Barranquilla and Soledad, developed in 2012 (Consorcio TPD-Epypsa, 2012). From this Plan we obtained information about land use, the location of commercial zones, the population, and the characteristics of the walking trips considering all purposes from each zone (TAZ). Additionally, we complemented the information with qualitative assessment of walkability at the street level, applied to primary roads and randomly selected local streets in the city. We also obtained information about intersection densities using the geographic information systems.

\subsection{Study area}

We applied the conceptual framework presented in 3.1 section to the conurbation of Barranquilla and Soledad (Figure 2(b)). The population of study area is approximately 1,700,000 inhabitants, living in an area of $221 \mathrm{~km}^{2}$, located on the northern coast of Colombia. The average temperature in the zone is around $29^{\circ} \mathrm{C}$, but pedestrians report a higher thermal sensation that is perceived as a barrier for walking at some times of the day.

The study area shows high social segregation patterns and marked inequities regarding infrastructure provision, location of activities, and access to services. For analysis purposes, we divided the whole study area into 348 zones (TAZ) considering socioeconomic characteristics (Figure 2(b)). We also used a socioeconomic strata (SES) variable as a proxy to represent income groups across the population. The SES variable is quite popular in Colombia to set subsidies to public services according to the expected income level (Cantillo-García et al., 2019). The variable range from 1 to 6, being SES one the lowest income people, while SES six the wealthiest. In this paper, SES 1 and 2 will represent low-income zones, SES 3 and 4 medium-income zones, and SES 5 and 6 highincome zones. Figure 2(a) show population density and income groups distribution in order to contextualise about population and social segregation patterns across Barranquilla and Soledad.

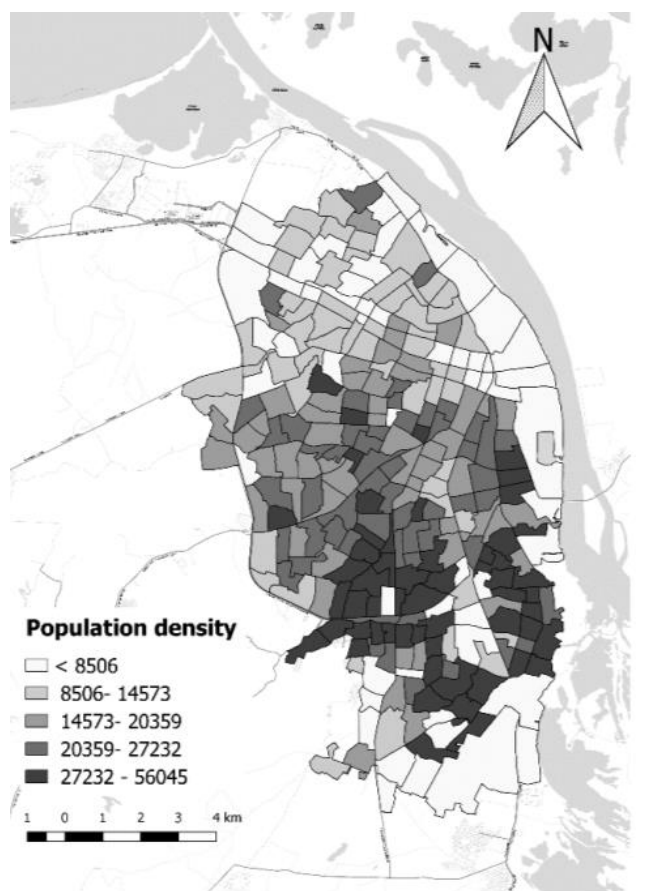

(a) Population density

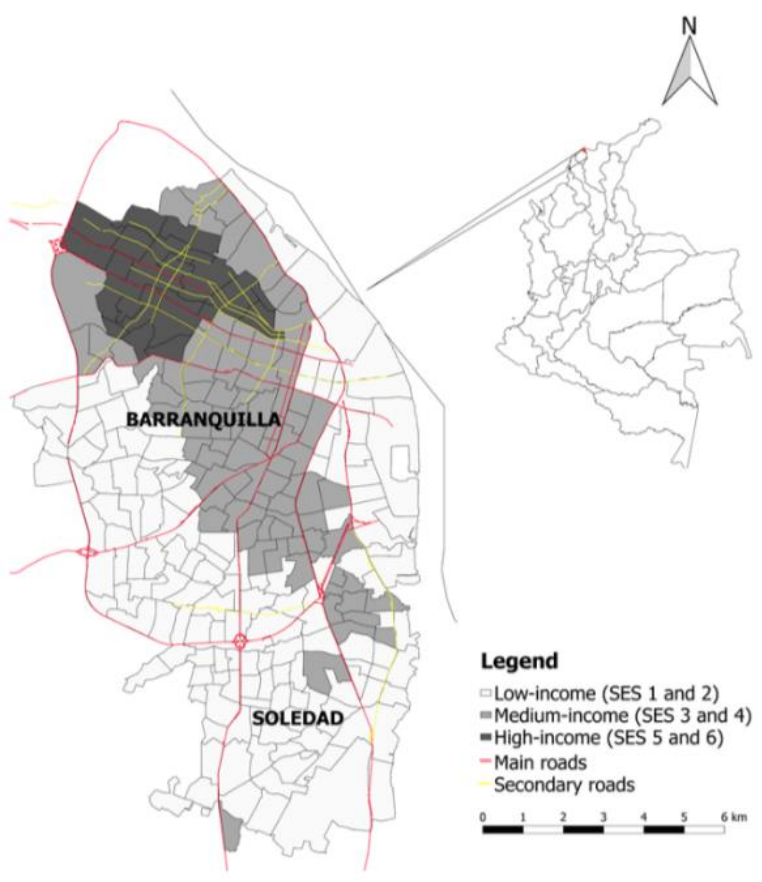

(b) Income groups and SES

Figure 2. Population density (population/ $\mathrm{km}^{2}$ ) and Income groups 
Urban growth in Soledad and southern zones in Barranquilla has been mostly informal, whereby most people who live in those zones are vulnerable to several risks. The population density in those vulnerable zones is higher than in northern zones (Figure 2(a)). Zones with higher population density match with low-income zones, while highincome zones have the lowest population density.

According to Barranquilla Cómo Vamos (2017), 44\% of the population lives in low-income neighbourhoodss, $42 \%$ to medium-income neighbourhoodss and only $14 \%$ remaining live in high-income neighbourhoods. In Soledad, $89 \%$ of the population lives in low-income zones (i.e. SES 1, 2), and $11 \%$ remaining in medium-income zones. Most of the population in both municipalities lives in low-income neighbourhoods facing limited access to public utilities, infrastructure and public transport services (Mertins, 2007).

Income is heavily correlated with private vehicle ownership, which is reflected across Barranquilla and Soledad (Consorcio TPD-Epypsa, 2012). Residents of northern neighbourhoods have higher average private vehicle ownership than people who live in southern zones (Figure 3(a)). In Barranquilla, according to the latest urban mobility plan (Consorcio TPD-Epypsa, 2012), most trips are made for mandatory purposes (roughly 70\%). Such high proportion of work and study trips increases the influence of land use and the spatial location of places for employment and education on mobility and accessibility patterns. Figure 3(b) shows the spatial distribution of job and study opportunities across the study area. Note that the northern zones and the downtown area concentrate most opportunities, in close proximity to the main road network in the region.

Zones with higher population density also match with zones with higher road network density (see Figure 4(a)). Despite such comparative higher availability of road infrastructure, the quality of the road network is poor. Most roads in the southern zones are not paved and do not meet the minimum width for appropriate circulation of buses and freight vehicles, nor the circulation of smaller vehicles travelling in opposite directions. Despite these limitations, empirical evidence shows most roads operate as two-lanes roads with two directions of circulation. Lack of adequate infrastructure leads to an inevitable mix of cars, buses, trucks, bicycles, and pedestrians being forced to share the road space (Consorcio TPD-Epypsa, 2012). This poses a serious road safety problem and a barrier to walkability ( Arellana et al., 2020; Larranaga et al., 2019). In northern zones and the city centre, most roads are suitable for commercial vehicles and public transport, and some degree of pedestrian infrastructure.

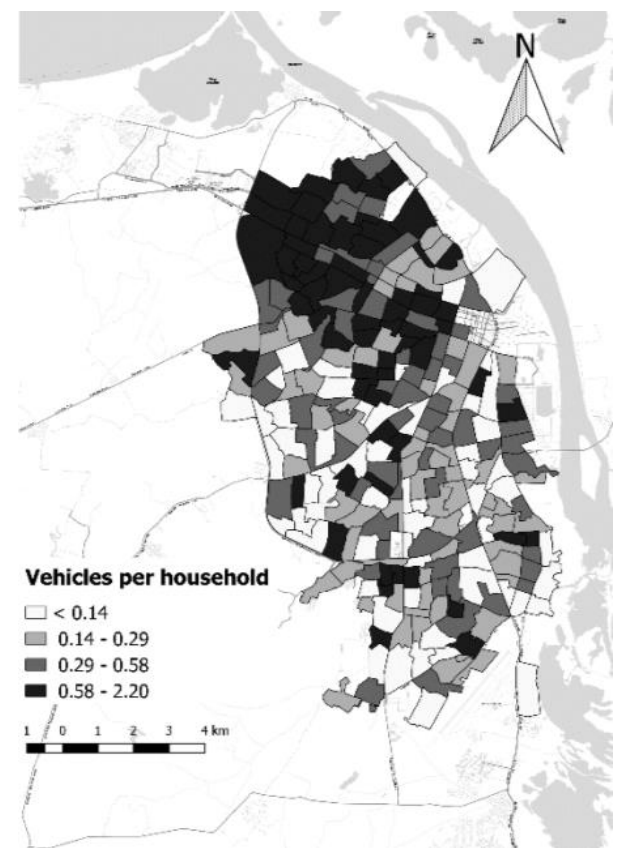

(a) Private vehicle ownership per household

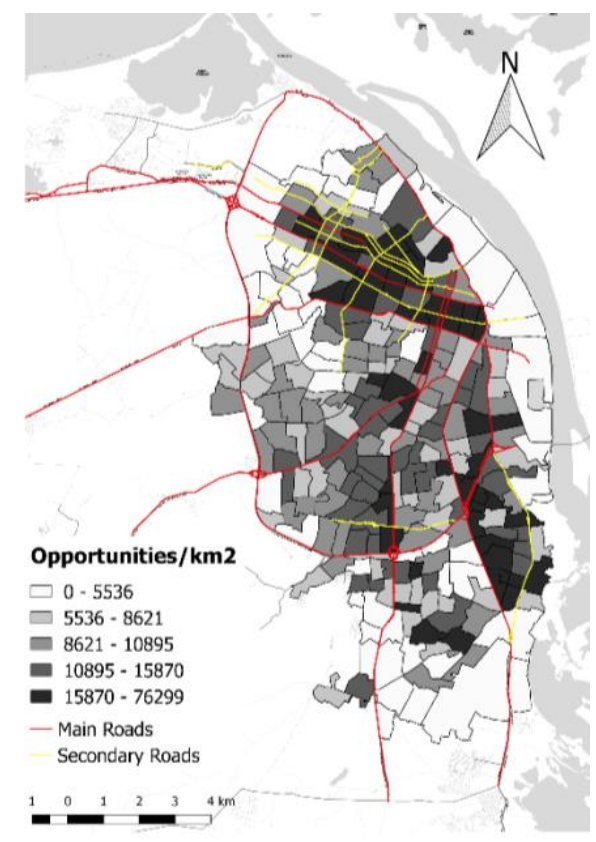

(b) Opportunities per square kilometre

Figure 3. Vehicle ownership per household and Opportunities per square kilometre

Walking times experienced by the different SES groups show considerable transport inequalities in the case study area. On average, pedestrians travelling from low-income zones spend 23.9 minutes, while those travelling from medium-SES and high-SES zones spend 17.8 minutes and 10.8 minutes, respectively. Figure 4(b) presents public 
transport density across Barranquilla and Soledad. These densities are higher in northern zones and downtown, which are the same zones that have the highest concentrations of work and study opportunities. Figure 4(c) shows that for individuals living in the periphery and southern zones of the city, higher walking times are a common occurrence. Regarding land use diversity (entropy), Figure 4(d) shows the land use entropy scores for all the zones in the study area. Northern zones, which are also the wealthiest, present higher levels of land use diversity. On average, high-SES level zones have a land use entropy score of 0.6, while medium and low-SES levels zone have an average score of 0.55 and 0.48 , respectively.

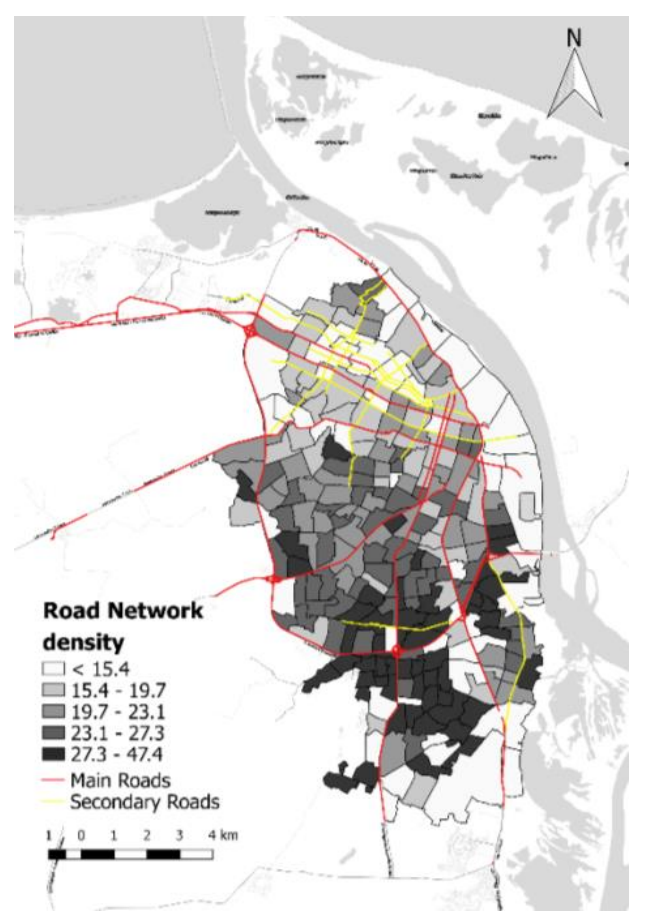

(a) Road network density

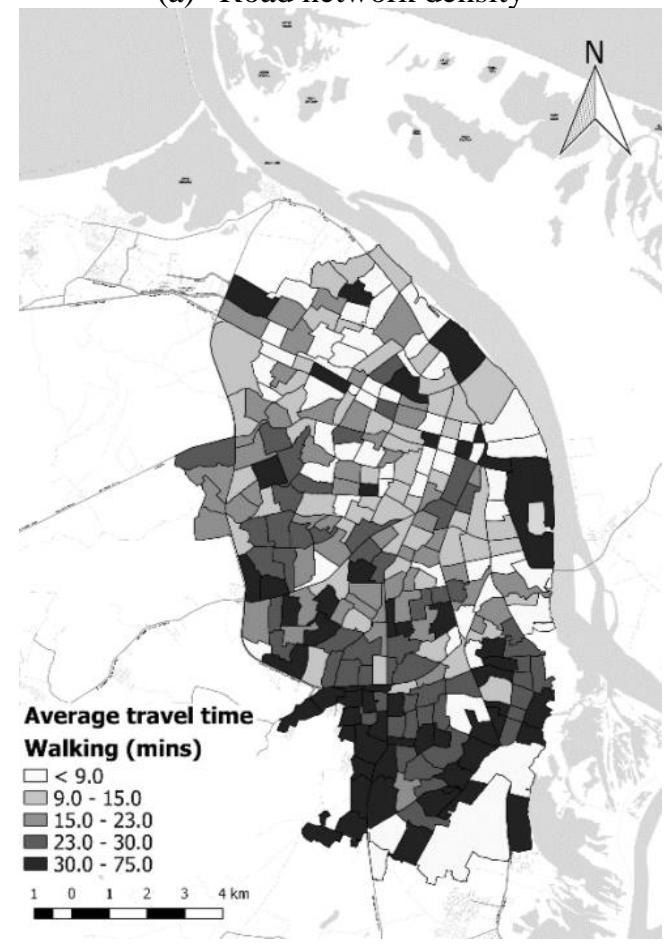

(c) Average walking time

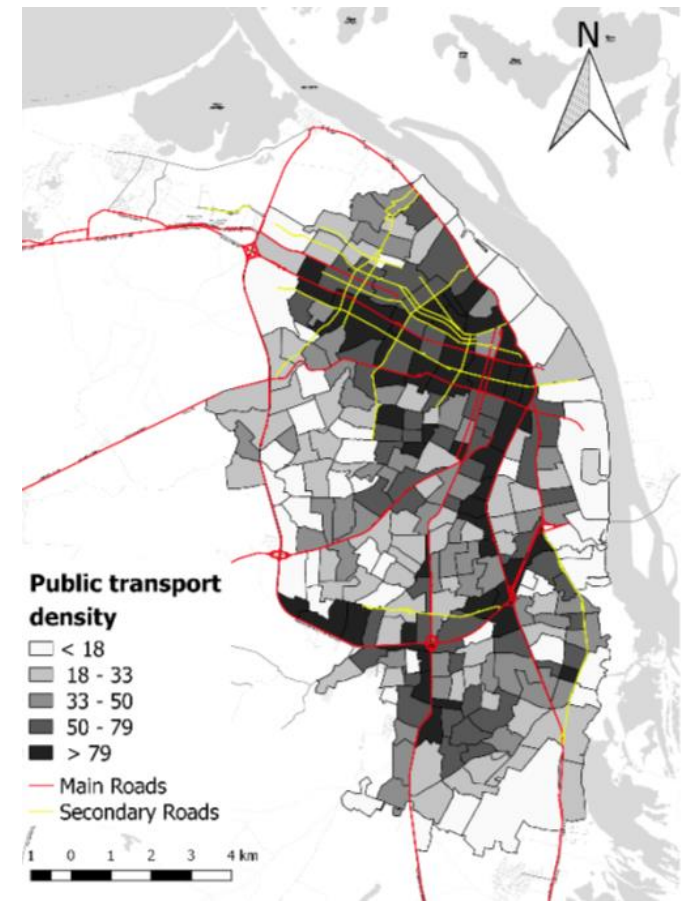

(b) Public transport density

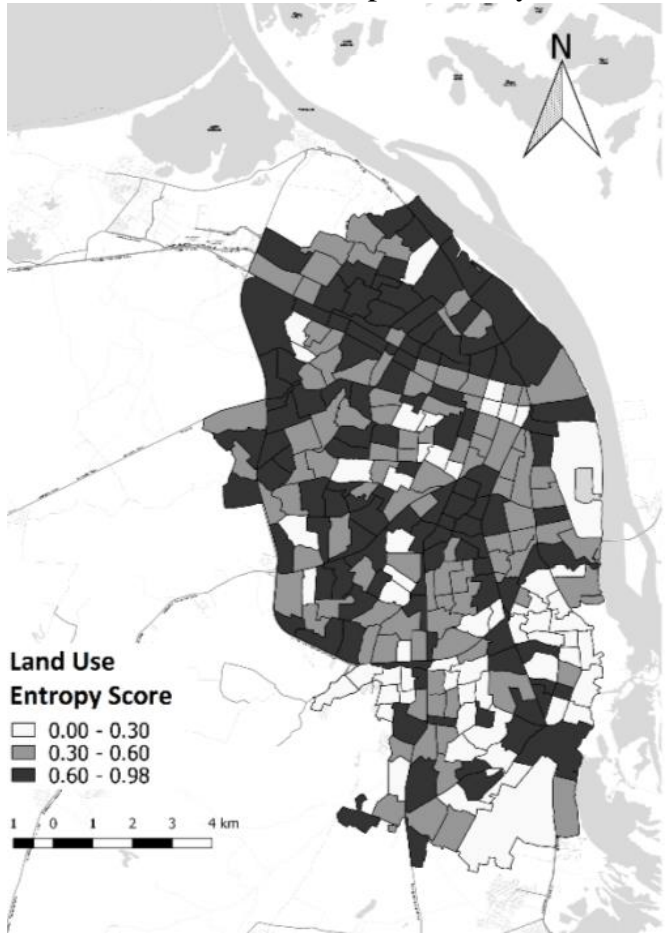

(d) Land Use entropy score 
Figure 4. Road network density, public transport density, average walking time and land use entropy score.

\section{Findings and discussion}

Walking conditions across Barranquilla and Soledad are examined in relation to different socioeconomic characteristics. We deployed a macro-scale potential accessibility measure and a meso-scale walkability index (WI). The use of these two metrics and the comparison of zones enables analysis of inequalities in the provision of pedestrian infrastructure across the cities.

Figure 5 presents the spatial distribution of meso-scale WI values considering both cities after computing equation 1 for all zones. Meso-scale WI values are not uniformly distributed across the region, showing considerable spatial variability. These values range between -5.83 and 9.21. On average, low-SES zones have a WI of 0.34 , while medium and high-SES zones have a WI around -0.23 and -1.08 , respectively. These results suggest and inverse relationship between income and walkability. In other words, in Barranquilla and Soledad the WI increases as income decreases. A somewhat counter-intuitive result.

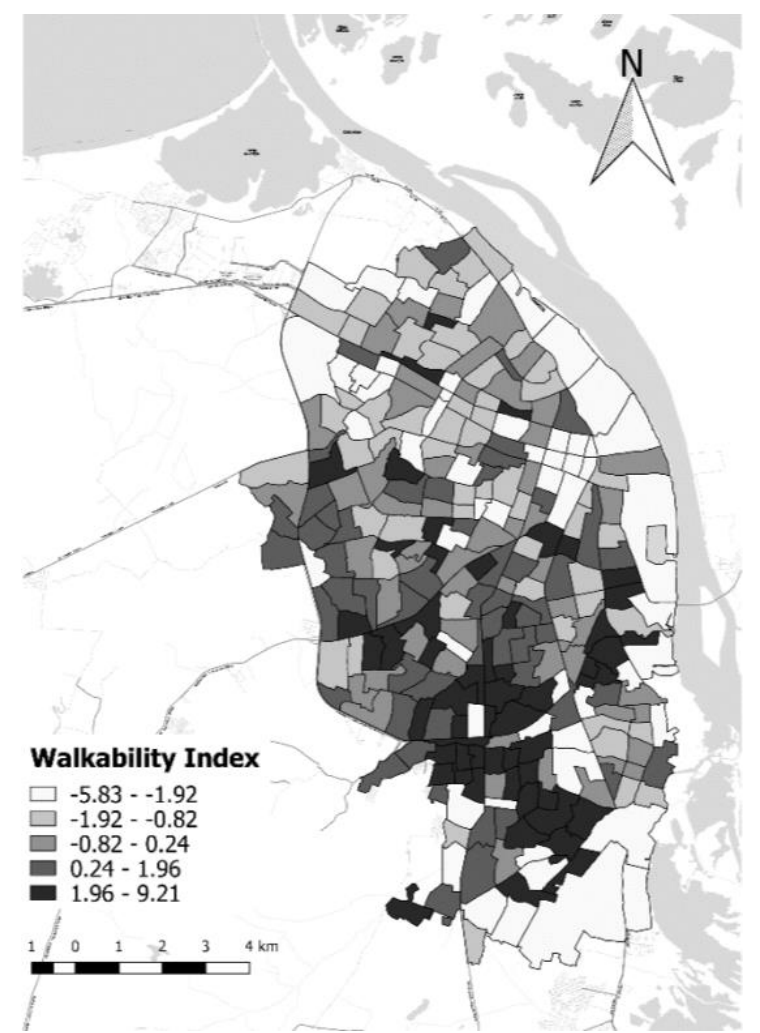

Figure 5. Meso-scale Walkability Index in Barranquilla and Soledad

Southern neighbourhoods have the highest WI values, which can be explained by their comparatively large observed population and intersection densities. Blocks in these zones are smaller than in other zones of Barranquilla and Soledad, partly as a result of a disorganised urban growth pattern marked by informal housing development and limited application and enforcement of urban planning and land-use regulations. The meso-scale WI formulation suggest that high densities promote walkable areas, which can lead to relevant findings for planning and decision-making in low-income areas of cities in the global south such as Barranquilla and Soledad. The WI suggests that lower-SES zones have the potential to facilitate walking trips by means of high concentration of people in the area, despite their lower land use entropy scores and commercial floor area densities in comparison with high-SES areas. 
Analysing the average standardised values of the components of the WI by SES group, we did not found zones that promote walkability strictly. Built environment characteristics seem to be out of alignment in terms of walking promotion, favouring the use of motorised vehicles. For example, in low-SES zones, the standardised value of population and intersection densities are positive $(Z=0.14$ and $Z=0.27$, respectively), while the standardised values for land use entropy score and commercial density are negative ( $Z=-0.15$ and $Z=-0.18$, respectively). For mediumSES zones, the standardised values for population and intersection densities are negative $(Z=-0.025$ and $Z=-.020$, respectively), whereas land use entropy score and commercial density are positive $(Z=0.14$ and $Z=0.06$, respectively). In high-SES zones there are similar patterns than the medium-SES zones, where the standardised values of population density and intersection density are negative $(Z=-0.67$ and $Z=-0.75$, respectively). In contrast, retail floor area and standardised land use entropy score values are positive ( $\mathrm{Z}=0.75$ and $\mathrm{Z}=0.35$, respectively). The above results suggest significant room for improvement in walking conditions in all zones and that large imbalances in the spatial distribution of economic, social and commercial opportunities across the BarranquillaSoledad conurbation has left a large untapped potential for the promotion of walking as a mechanism for local access, particularly in lower-income populations. The dissagregated resuts for the estimation of WIs point at the need for a larger role of urban planning and policy-making in improving BE characteristics associated with walkability and the promotion of walkable neighbourhoods that may redefine current car-oriented development trajectories.

Given the size of the Barranquilla-Soledad conurbation, it was not possible to collect micro-scale walkability measures for all streets in the network. Despite such limitation, we deployed a qualitative assessment of walkability for randomly selected roads in each zone, which despite not being representative suggests a marked deficit of appropriate walking infrastructure in low-SES zones. In line with Herrmann-Lunecke et al. (2020), we found that high-SES zones in Barranquilla have better quantitative and qualitative availability of pavements and other pedestrian infrastructure, making higher-income neighbourhoods more pedestrian-friendly than other zones in the two cities. This is consistent with literature in Latin American cities that suggests that highly attractive and wealthy areas experience a self-reinforcing cycle of improvements in connectivity and quality of the public space, while lower-income and peripheral neighbourhoods tend to be bypassed in the process of infrastructure and urban development (Oviedo \& Dávila, 2016).

Pedestrian infrastructure investments do not ameliorate the differences found between zones. The evidence suggests that in Barranquilla, most investments in pedestrian infrastructure and public spaces have focused on the northern zones, which already have better infrastructure conditions for pedestrians. This leads to fragmented connectivity and highly unequal urban environments as well as higher exposure of already vulnerable pedestrians in lower-income neighbourhoods to the various health and environmental externalities associated with unsafe spaces for walking. Sidewalks in the wealthiest zones are better-equipped, with some ramps, and pavement surfaces. The width of the sidewalks in these zones is higher than in southern zones of Barranquilla and in the whole Soledad, where most sidewalks have widths of 1 meter $(3.28 \mathrm{ft}$ ) or less. Pavements in Soledad tend to be unsurfaced and uneven which represents another physical constraint for pedestrian mobility and access.

Complementary to the analysis of walkability indices, potential pedestrian accessibility indices suggest that people in the northern zones and the city centre of Barranquilla can access to more opportunities by walking than people in the southern zones and Soledad (Figure 6). Ironically, individual mobility in these zones is highly reliant on private transport modes. The potential accessibility per capita for pedestrians in high-SES zones is 2.44 times higher than the average for the whole study area. Meanwhile, the potential accessibility values for medium-SES and low-SES zones are $73 \%$ and $88 \%$ of the average, respectively highlighting already marked inequalities suggested by earlier findings and previous studies in the context of Barranquilla and Soledad (Davila \& Oviedo, 2018).

Comparisons among income groups of the macro-scale pedestrian accessibility measure suggests that potential accessibility in medium-income zones is $30 \%$ of high-income accessibility. Furthermore, accessibility per capita for pedestrians in low-income zones is $36 \%$ of the one for high-income zones. On average, accessibility per capita in Barranquilla is 1.25 times higher than the average for the whole zone. In Soledad, this measure only represents $25 \%$ of the accessibility per capita of both municipalities. These results suggest marked spatial inequalities for pedestrians to access locally relevant opportunities for the accumulation of social, economic and cultural capital (Schwanen et al., 2015). The high concentration of activities (e.g. workplaces, study zones, commercial zones, banking zones, among others) in the northern zones and the Barranquilla's city centre impose high distances and public transport-dependency for low-income inhabitants living in the peripheries, limiting their ability to access relevant opportunities without using motorised transport modes. 
When comparing Figures 5 and 6, it is interesting to highlight that the spatial distribution of meso-scale walkability and macro-scale pedestrian accessibility measures differ. Potential accessibility is higher in the wealthiest zones (i.e. the northern zones), which also present lower WI values. The opposite happens in low-SES areas, where meso-scale WI values are higher than in high-SES zones but the potential accessibility is considerably lower. Figure 7 supports the above by presenting the mean values of both measures (i.e. the macro-scale pedestrian accessibility and the meso-scale WI) for each income group. The figure suggests a lack of coordination between walking demand and supply catering for these trips. This imbalance between supply and demand for walking trips suggests that unfortunately, zones with the highest potential of being walkable are those facing more barriers to walk.

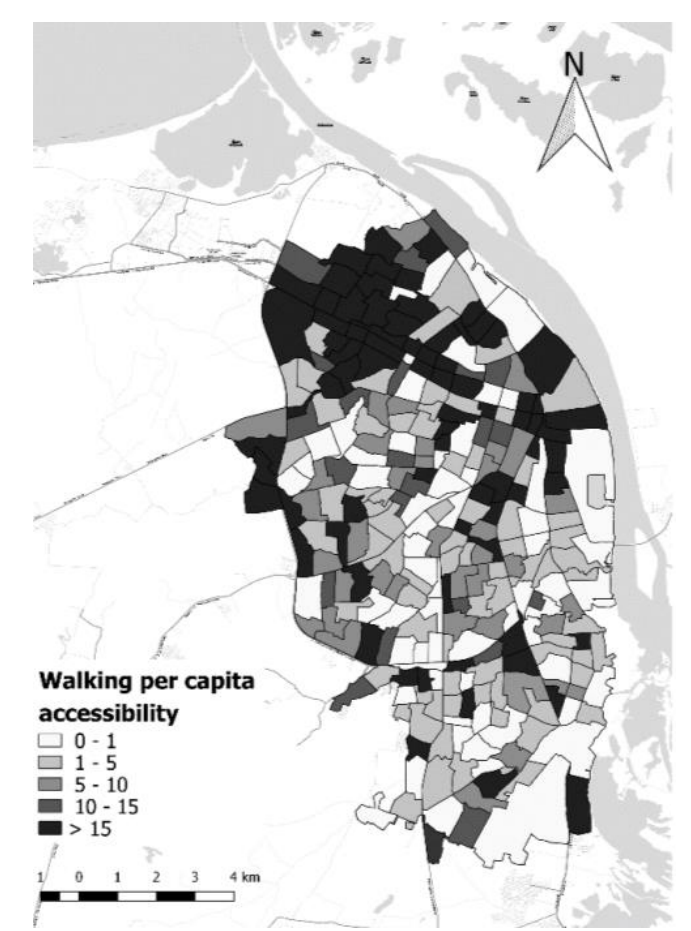

Figure 6. Potential pedestrian accessibility per capita in Barranquilla and Soledad

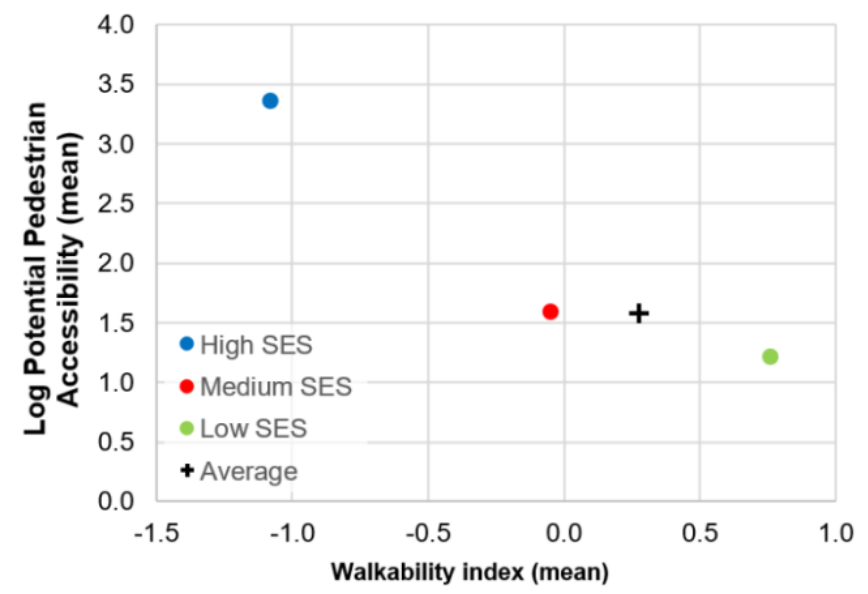

Figure 7. Average values for macro-scale and meso-scale accessibility measures by income group

To provide evidence on distributional effects of walkability indices and we estimated inequality indices that visibilise the considerable differences in potential pedestrian accessibility for citizens in the study area. Using a similar approach to the one suggested by Guzman et al. (2017) to measure relative accessibility levels of the population in each zone, we estimated Gini coefficients throughout the study area using Lorenz curves. We 
adjusted the Gini index to reflect potential pedestrian accessibility. This index ranges from 0 to 1 , where 0 corresponds to perfect equality (i.e. everyone experiences the same accessibility) and 1 refers to perfect inequality (i.e. one individual has all the accessibility, while the rest none). The coefficient for this case was 0.63, confirming the considerable differences in pedestrian accessibilities across the study area. Figure 8 shows the Lorenz curve, where we compare the pedestrian accessibility measure with the population by TAZ. The result suggests that $80 \%$ of the inhabitants of Barranquilla and Soledad shared only $30 \%$ of the potential accessibility, which refers to the potential access to opportunities by walking.

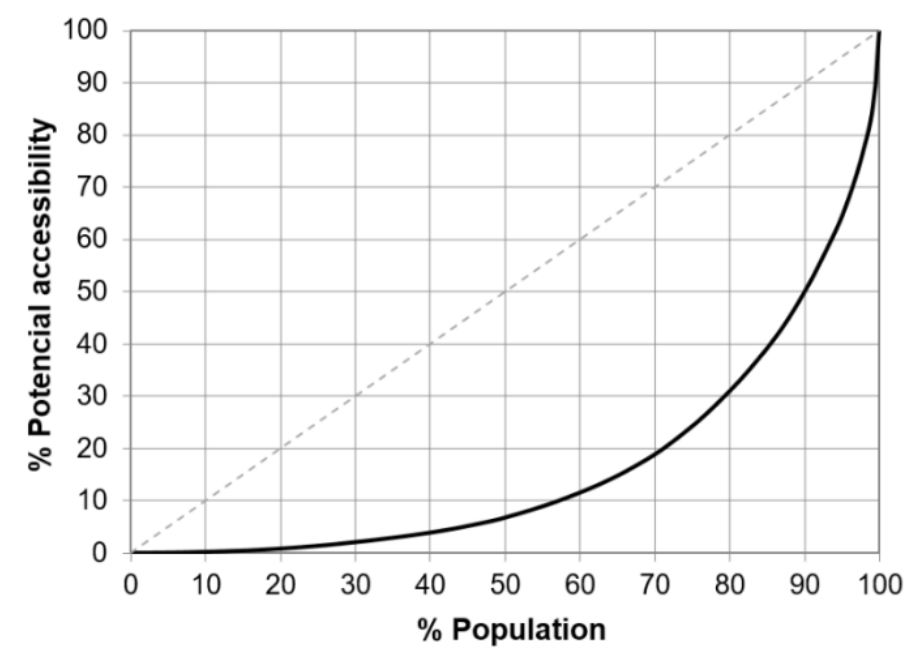

Figure 8. Lorenz curve of population

A proxy for vertical equality across the income groups also suggests considerable disparities among socioeconomic groups. The high-SES group obtained a Gini coefficient of 0.47 , while values for medium-SES and low-SES populations were 0.68 and 0.60 , respectively. Although the high-SES group has the most equitable distribution of potential accessibility within its zones, this is a reflection of the high concentration of opportunities in the study area. This high concentration of activities coupled with spatial inequalities in the provision of pedestrian infrastructure, leads to social segregation and marked spatial inequalities. The observed situation is the result of a historical promotion of motorised vehicles, dismissing the adoption of sustainable mobility policies that encourage active transport modes. Surely accessibility and equity issues should be incorporated in the development agenda for the cities, also considering the implementation of planning and transport policies to discourage the use of motorised transport (Arellana et al., 2012b; Guzman et al., 2020; Orozco-Fontalvo et al., 2020; Ortúzar, 2019; Ramos et al., 2017).

The qualitative assessment of the walkability conditions at the micro-scale on the selected segments in each zone allowed us to dig deeper and elaborate more on the inequalities in the provision of pedestrian infrastructure among different socioeconomic sectors in the Barranquilla and Soledad. Figure 9 shows the differences in the quality of the built environment by SES. The built environment in high-SES zones has better quality. These zones usually provide wider, and more continuous sidewalks than the rest of the city. Their sidewalks are usually paved and in fair conditions, without the presence of rubbish or obstructions that impede pedestrian access. Intersections have pedestrian ramps that facilitate access to people with disabilities (figure 9a). In the medium zones, pedestrian facilities have lower quality than in high-SES zones. Sidewalks are narrower, with more obstructions, and are not that continuous compared to wealthier zones (figure 9b). Most pedestrian zones are occupied by parking or not well maintained. Finally, the built environment quality in low-SES zones is mostly precarious (figure 9c). Most of the roads have no paved sidewalks, or they do not even exist. People have to compete for space with cars, motorcycles, and buses. Those road segments with a sidewalk, frequently are occupied by debris or are not continuous. Also, lighting is poor. Security conditions are more extreme than those experienced in wealthier zones of the city. 

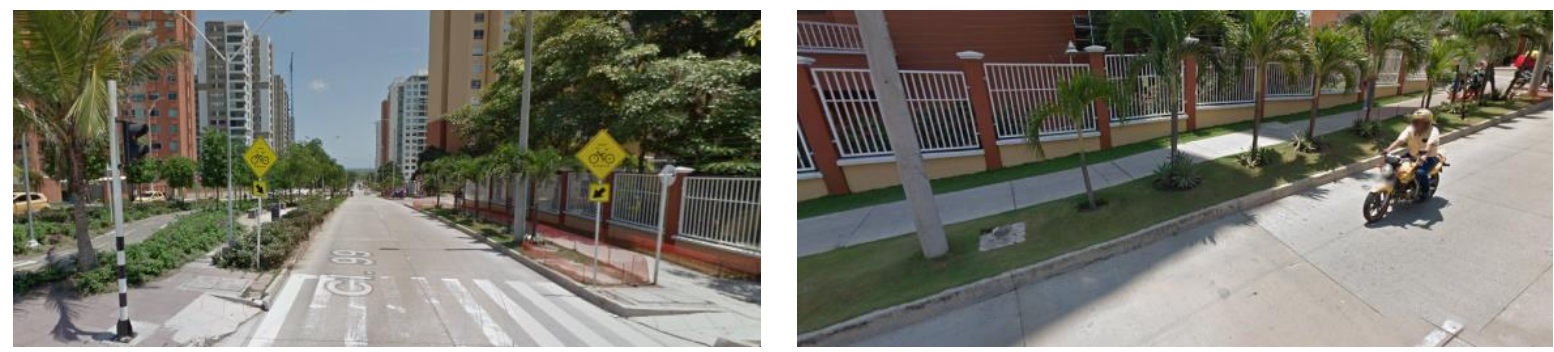

(a) Built environment high-SES zones
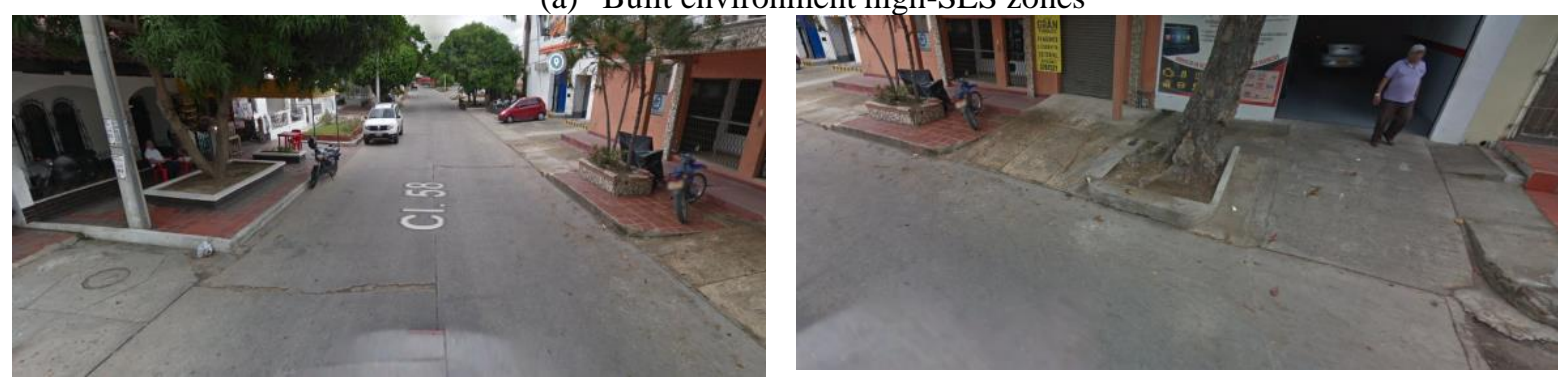

(b) Built environment medium-SES zones
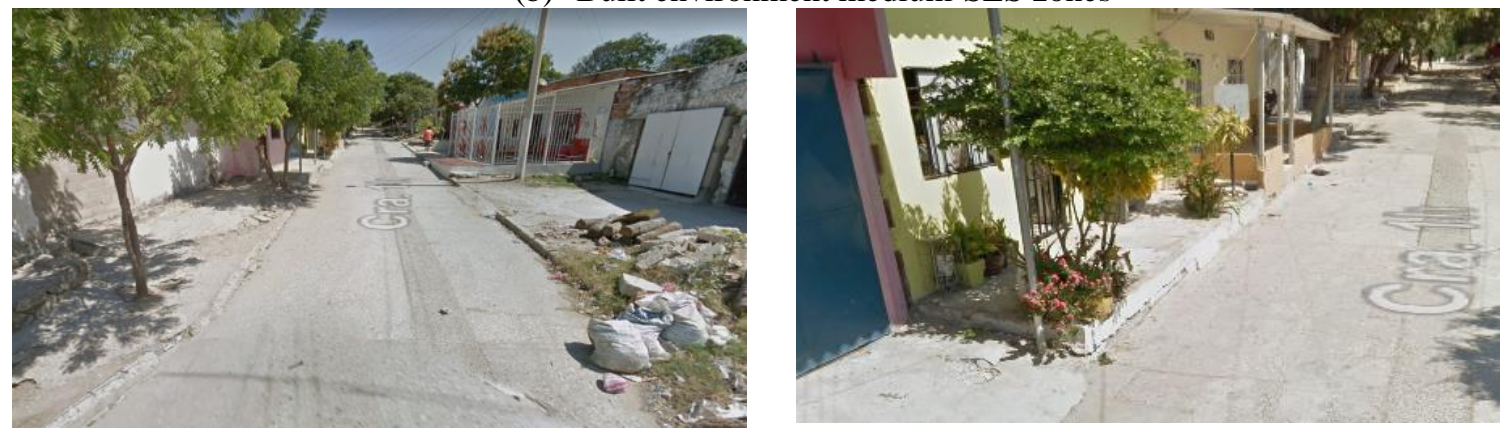

(c) Built environment low-SES zones

Figure 9. Quality of the built environment in different zones of the city.

Therefore, after comparing the quality of their built environment qualitatively, we conclude that the best quality is in wealthier areas, where people tend to walk less and highly mobilise by private vehicles, mostly because they have access to them. In contrast, the lowest SES zones have the most precarious condition of the built environment, which affects pedestrian safety, exhibit insecurity, and undermines the possibility of the pedestrian to mobilise across space adequately. Ironically, despite the poor conditions of the pedestrian infrastructure in the lowest SES areas, people have a greater potential to use the walk. The high population and road densities in low income zones make walking perhaps more attractive than more expensive transport modes, which is exacerbated because people do not have access or afford motorised modes.

\section{Conclusions}

This paper compares supply-centred and demand-centred measures of walkability and identifies equality gaps in access to opportunities for pedestrians considering different socioeconomic groups in Barranquilla and Soledad. The use of a meso-scale measure of walkability and a macro-scale measure of pedestrian accessibility enabled a critical assessment of how people walk within zones and identifying which areas offer better-suited built environment characteristics for walking.

Our analysis suggests that walkability indices are higher in the lower-income southern zones of the study area. These higher walkability indices in zones with higher degrees of poverty and socioeconomic disadvantage points at potentially favourable built environment characteristics for the promotion of walking. However, in the absence of other essential built environment characteristics such as availability of essential opportunities (e.g. job and study opportunities) and the presence of specific barriers to walkability the result is a travel demand heavily reliant on other transport modes. 
By contrast, findings associated with potential pedestrian accessibility indices was higher in the northern and downtown areas, where wealthier people live. These potential accessibility values reveal that people who can capture the highest benefits of walking in the city are those who live in zones with medium and high socioeconomic levels, who paradoxically choose to use more motorised public and private travel alternatives. The strong mismatch between planning and investment and travel needs and preferences lead to more transport and socially advantaged populations facing less barriers to walkability than those living in more disadvantaged zones of the city.

Travel times experienced by pedestrians are in line with the above conclusions. People from low-income zones walk longer distances than their higher-income counterparts. This analysis shows strong inequalities marked by differences in income. Shorter walking times can be associated with the land use entropy scores found in the northern zones and downtown Barranquilla. Higher diversity of land-use encourages pedestrians to walk more. Current built environment characteristics, especially in relation to land-use mix, increases the ability of wealthier populations to access more opportunities than lower-income citizens. Considering all results together, it is possible to infer that urban development patterns in Barranquilla and Soledad and the historically segregating and caroriented policies, planning and infrastructure development practices have resulted in barriers for pedestrians in low-SES zones. This calls for improvements in spatial and social targeting of resources and walking-centred policies in search for higher equality. Walkability and accessibility indices can be a powerful instrument for urban planning and policy-making in improving built environment characteristics associated with walkability, serving as indicators for the spatial analysis of localised needs for the promotion of walking and redressing inequalities in pedestrian infrastructure provision.

Our findings also suggest the need to analyse other contexts and include other built environment characteristics in future research. The usefulness of the framework and its results should be complemented with analyses, including additional quantitative information, such as pedestrian counts throughout the city or planning models to examine active mobility patterns derived from origin-destination surveys. Such analyses could help in observing what the walkability conditions in areas that concentrate more walking trips are. Also, mixed methods that include qualitative information about mobility practices and experiences of people belonging to different groups (e.g. age, gender, income, physical abilities, etc.) may enrich the analysis.

Distributional analysis exploring structural inequalities should consider other transport and socially disadvantaged groups marked by differences in gender, age, ethnicity and disability, among other intersecting social identities. Finally, we recommend extending the analysis by including micro-scale walkability measures for all the roads in the network considering factors such as the quality and width of sidewalks, security perceptions, and other relevant objective and subjective determinants of walkability; and for macro-scale we recommend including walking information of main stage of the trips is by public transport. This paper constitutes a contribution to the still scarce literature on walkability and inequalities in global south cities, and we expect it to serve as basis for future research developing further such a relevant research agenda for urban transport policy and practice.

\section{References}

Adams, M., Frank, L. D., Schipperijn, J., Smith, G., Chapman, J., Christiansen, L., Coffee, N., Salvo, D., du Toit, L., Dygryn, J., Ferreira, A., Lai, P., Mavoa, S., Pinzón, J., Van de Weghe, N., Cerin, E., Davey, R., Macfarlane, D., Owen, N., \& Sallis, J. (2014). International variation in neighborhood walkability, transit, and recreation environments using geographic information systems: the IPEN adult study. International Journal of Health Geographics, 13, 43.

Adams, M., Todd, M., Kurka, J., Conway, T., Cain, K., Lawrence, F., \& Sallis, J. (2015). Patterns of Walkability, Transit, and Recreation Environment for Physical Activity. American Journal of Preventive Medicine, 49(6), 878-887. https://doi.org/110.1016/j.bbi.2017.04.008

Alfonzo, M. A. (2005). To walk or not to walk? The hierarchy of walking needs. Environment and Behavior, 37(6), 808-836. https://doi.org/10.1177/0013916504274016

Arellana, J., Daly, A., Hess, S., Ortúzar, J. de D., \& Rizzi, L. I. (2012). Development of Surveys for Study of Departure Time Choice Two-Stage Approach to Efficient Design. 2303, 9-18. https://doi.org/10.3141/230302

Arellana, J., Saltarín, M., Larrañaga, A. M., Alvarez, V., \& Henao, C. A. (2020). Urban walkability considering pedestrians' perceptions of the built environment: a 10-year review and a case study in a medium-sized city in Latin America. Transport Reviews, 40(2), 183-203. https://doi.org/10.1080/01441647.2019.1703842

Barranquilla Cómo vamos. (2017). Encuesta de Percepción. Barranquilla cómo vamos 2017.

Bocarejo, J. P., \& Oviedo, D. (2012). Transport accessibility and social inequities: a tool for identification of 
mobility needs and evaluation of transport investments. Journal of Transport Geography, 24, 142-154. https://doi.org/10.1016/j.jtrangeo.2011.12.004

Bödeker, M. (2018). Walking and walkability in pre-set and self-defined neighborhoods: A mental mapping study in older adults. International Journal of Environmental Research and Public Health, 15(7). https://doi.org/10.3390/ijerph15071363

Boyce, C. (2010). Walkability, social inclusion and social isolation and street redesign. Built Environment, 36(4), 461-473. https://doi.org/10.2148/benv.36.4.461

Braun, L. M., Rodriguez, D. A., Song, Y., Meyer, K. A., Lewis, C. E., Reis, J. P., \& Gordon-Larsen, P. (2016). Changes in walking, body mass index, and cardiometabolic risk factors following residential relocation: Longitudinal results from the CARDIA study. Journal of Transport and Health, 3(4), 426-439. https://doi.org/10.1016/j.jth.2016.08.006

Cantillo-García, V., Guzman, L. A., \& Arellana, J. (2019). Estrato socioeconómico como variable sustituta del ingreso del hogar en la investigación de transporte. Evaluación para Bogotá, Medellín, Cali y Barranquilla. DYNA; Vol. 86, Núm. $211 \quad$ (2019)DO $\quad$ - 10.15446/Dyna.V86n211.81821 https://revistas.unal.edu.co/index.php/dyna/article/view/81821

Cervero, R., \& Kockelman, K. (1997). Travel demand and the 3 Ds: Density, diversity, and design. Transportation Research Part D, 2(3), 199-219. https://doi.org/https://doi.org/10.1016/S1361-9209(97)00009-6

Choi, S., Choo, S., \& Kim, S. (2019). Exploring the influences of compact development on zone-based travel patterns: a case study of the Seoul metropolitan area. Transportation Letters, 1-13. https://doi.org/10.1080/19427867.2019.1589716

Christiansen, L. B., Madsen, T., Schipperijn, J., Ersbøll, A. K., \& Troelsen, J. (2014). Variations in active transport behavior among different neighborhoods and across adult life stages. Journal of Transport and Health, 1(4), 316-325. https://doi.org/10.1016/j.jth.2014.10.002

Clark, A. F., Scott, D. M., \& Yiannakoulias, N. (2014). Examining the relationship between active travel, weather, and the built environment: a multilevel approach using a GPS-enhanced dataset. Transportation, 41(2), 325338. https://doi.org/10.1007/s11116-013-9476-3

Consorcio TPD-Epypsa. (2012). Formulación del Plan Maestro de Movilidad del distrito de Barranquilla.

Currie, G., Richardson, T., Smyth, P., Vella-Brodrick, D., Hine, J., Lucas, K., Stanley, J., Morris, J., Kinnear, R., \& Stanley, J. (2010). Investigating links between transport disadvantage, social exclusion and well-being in Melbourne - Updated results. Research in Transportation Economics, 29(1), 287-295. https://doi.org/10.1016/j.retrec.2010.07.036

Davila, J. D., \& Oviedo, D. (2018). Masstransit, social inequalities and BRT-driven (IM) mobilities in Barranquilla, Colombia. In J. Hernández García, A. García Jerez, \& B. B. Beza (Eds.), Urban Space: experiences and Reflections from the Global South (pp. 173-200). Sello Editorial Javeriano Cali.

de Sa, E., \& Ardern, C. I. (2014). Neighbourhood walkability, leisure-time and transport-related physical activity in a mixed urban-rural area. PeerJ, 2, e440. https://doi.org/10.7717/peerj.440

Ellis, G., Hunter, R., Tully, M. A., Donnelly, M., Kelleher, L., \& Kee, F. (2016). Connectivity and physical activity: using footpath networks to measure the walkability of built environments. Environment and Planning B-Planning \& Design, 43(1), 130-151. https://doi.org/https://doi.org/10.1177/0265813515610672

Ewing, R., \& Cervero, R. (2010). Travel and the Built Environment. Journal of the American Planning Association, 76(3), 265-294. https://doi.org/10.1080/01944361003766766

Forsyth, A., \& Southworth, M. (2008). Guest editorial: Cities afoot - Pedestrians, walkability and urban design. Journal of Urban Design, 13(1), 1-3. https://doi.org/10.1080/13574800701816896

Frank, L. D., Kerr, J., Chapman, J., \& Sallis, J. (2007). Urban form relationships with walk trip frequency and distance among youth. American Journal of Health Promotion, 21(4 SUPPL.), $305-311$. https://doi.org/10.4278/0890-1171-21.4s.305

Frank, L. D., Sallis, J., Saelens, B., Leary, L., Cain, L., Conway, T. L., \& Hess, P. M. (2010). The development of a walkability index: Application to the neighborhood quality of life study. British Journal of Sports Medicine, 44(13), 924-933. https://doi.org/10.1136/bjsm.2009.058701

Frank, R. H., \& Bernanke, B. (2007). Principles of Microeconomics (3rd Editio). McGraw-Hill/Irwin.

Gardner, K., Johnson, T., Buchan, K., \& Pharoah, T. (1996). Developing a pedestrian strategy for London. Transport Policy and Its Implementation : Proceedings of Seminar B Held at the PTRC European Transport Forum, Brunel University, England, 2-6 September 1996., 400. http://www.worldcat.org/title/transportpolicy-and-its-implementation-proceedings-of-seminar-b-held-at-the-ptrc-european-transport-forumbrunel-university-uxbridge-england-2-6-september-1996/oclc/924703888\#.WcEW18PVn00.mendeley

Geurs, K. T., \& van Wee, B. (2004). Accessibility evaluation of land-use and transport strategies: Review and research directions. Journal of Transport Geography, 12(2), 127-140. https://doi.org/10.1016/j.jtrangeo.2003.10.005 
Gutiérrez, M., Cantillo, V., Arellana, J., \& Ortúzar, J. de D. (2020). Estimating bicycle demand in an aggressive environment. International Journal of Sustainable Transportation. https://doi.org/10.1080/15568318.2020.1734886

Guzman, L.A., Arellana, J., \& Alvarez, V. (2020). Confronting congestion in urban areas: Developing Sustainable Mobility Plans for public and private organizations in Bogotá. Transportation Research Part A: Policy and Practice, 134, 321-335. https://doi.org/10.1016/j.tra.2020.02.019

Guzman, L A, Oviedo, D., \& Rivera, C. (2017). Assessing equity in transport accessibility to work and study: The Bogotá region. Journal of Transport Geography, 58, 236-246. https://doi.org/10.1016/j.jtrangeo.2016.12.016

Guzman, L. A., Peña, J., \& Carrasco, J. A. (2020). Assessing the role of the built environment and sociodemographic characteristics on walking travel distances in Bogotá. Journal of Transport Geography, 88, 102844. https://doi.org/10.1016/j.jtrangeo.2020.102844

Herrmann-Lunecke, M. G., \& Mora, R. (2018). The layered city: pedestrian networks in downtown Santiago and their impact on urban vitality. Journal of Urban Design, 23(3), 336-353. https://doi.org/10.1080/13574809.2017.1369869

Herrmann-Lunecke, M. G., Mora, R., \& Sagaris, L. (2020). Persistence of walking in Chile: lessons for urban sustainability. Transport Reviews, 40(2), 135-159. https://doi.org/10.1080/01441647.2020.1712494

Instituto Nacional de Medicina Legal y Ciencias Forenses. (2019). Forensis 2018, DATOS PARA LA VIDA. https://www.medicinalegal.gov.co/cifras-estadisticas/forensis

Kim, S., Park, S., \& Lee, J. S. (2014). Meso- or micro-scale? Environmental factors influencing pedestrian satisfaction. Transportation Research Part D: Transport and Environment, 30, 10-20. https://doi.org/10.1016/j.trd.2014.05.005

Larranaga, A. M., Arellana, J., Rizzi, L. I., Strambi, O., \& Cybis, H. B. B. (2019). Using best-worst scaling to identify barriers to walkability: a study of Porto Alegre, Brazil. Transportation, 46(6), 2347-2379. https://doi.org/10.1007/s11116-018-9944-X

Larranaga, A. M., Bettella Cybis, H. B., Arellana, J., Rizzi, L. I., \& Strambi, O. (2016). Estimando a importância de características do ambiente construído para estimular bairros caminháveis usando o best-worst scaling. TRANSPORTES, 24(2), 13. https://doi.org/10.14295/transportes.v24i2.1091

Larrañaga, A. M., Rizzi, L. I., Arellana, J., Strambi, O., \& Cybis, H. B. B. (2014). The Influence of Built Environment and Travel Attitudes on Walking: A Case Study of Porto Alegre, Brazil. International Journal of Sustainable Transportation. https://doi.org/10.1080/15568318.2014.933986

Lee, R. J., Sener, I. N., \& Jones, S. N. (2017). Understanding the role of equity in active transportation planning in the United States. Transport Reviews, 37(2), 211-226. https://doi.org/10.1080/01441647.2016.1239660

Levy, C. (2013). Travel choice reframed:“deep distribution” and gender in urban transport. Environment and Urbanization. https://doi.org/https://doi.org/10.1177/0956247813477810

Lucas, K. (2019). A new evolution for transport-related social exclusion research? Journal of Transport Geography, 81, 102529. https://doi.org/10.1016/j.jtrangeo.2019.102529

Lucas, K., \& Jones, P. (2012). Social impacts and equity issues in transport: An introduction. Journal of Transport Geography, 21, 1-3. https://doi.org/10.1016/j.jtrangeo.2012.01.032

Lucas, K., van Wee, B., \& Maat, K. (2016). A method to evaluate equitable accessibility: combining ethical theories and accessibility-based approaches. Transportation, 43(3), 473-490. https://doi.org/10.1007/s11116-015-9585-2

Mackett, R. L., Achuthan, K., \& Titheridge, H. (2008). AMELIA: A tool to make transport policies more socially inclusive. Transport Policy, 15(6), 372-378. https://doi.org/10.1016/j.tranpol.2008.12.007

Maibach, E., Steg, L., \& Anable, J. (2009). Promoting physical activity and reducing climate change: Opportunities to replace short car trips with active transportation. Preventive Medicine, 49(4), 326-327. https://doi.org/10.1016/j.ypmed.2009.06.028

Mertins, G. (2007). Estudios Urbanos -Regionales desde el Caribe: El crecimiento “moderno" espacial- urbano en Barranquilla: ¿Planeación pública-oficial o manejo del sector privado? Memorias: Revista Digital de Historia y Arqueología Desde El Caribe Colombiano, 4(7), 114-128.

Moura, F., Cambra, P., \& Gonçalves, A. B. (2017). Measuring walkability for distinct pedestrian groups with a participatory assessment method: A case study in Lisbon. Landscape and Urban Planning, 157, $282-296$. https://doi.org/10.1016/j.landurbplan.2016.07.002

Orozco-Fontalvo, M. J., Martínez, S., Arellana, J., \& Vega, L. (2020). A BWS Application to Identify Factors Affecting User Preferences for Parking Choices at University Campuses. Ingenieria y Universidad, 24(1). https://doi.org/10.11144/Javeriana.iyu24.aifa

Orozco-Fontalvo, M., Soto, J., Arévalo, A., \& Oviedo-Trespalacios, O. (2019). Women's perceived risk of sexual harassment in a Bus Rapid Transit (BRT) system: The case of Barranquilla, Colombia. Journal of Transport 
and Health, 14, 100598. https://doi.org/10.1016/j.jth.2019.100598

Ortúzar, J. de D. (2019). Sustainable Urban Mobility: What Can Be Done to Achieve It? In Journal of the Indian Institute of Science (Vol. 99, Issue 4, pp. 683-693). Springer. https://doi.org/10.1007/s41745-019-00130-y

Ortúzar, J. de D., \& Willumsen, L. G. (2011). Modelling Transport (Fourth). John Wiley \& Sons, Ltd.

Oviedo, D., \& Dávila, J. D. (2016). Transport, urban development and the peripheral poor in Colombia - Placing splintering urbanism in the context of transport networks. Journal of Transport Geography. https://doi.org/10.1016/j.jtrangeo.2016.01.003

Oviedo, D., \& Titheridge, H. (2016). Mobilities of the periphery: Informality, access and social exclusion in the urban fringe in Colombia. Journal of Transport Geography. https://doi.org/10.1016/j.jtrangeo.2015.12.004

Pereira, R. H. M., Schwanen, T., \& Banister, D. (2017). Distributive justice and equity in transportation. Transport Reviews, 37(2), 170-191. https://doi.org/10.1080/01441647.2016.1257660

Pucci, P., \& Vecchio, G. (2019). Enabling mobilities: Reinterpreting concepts and tools. In SpringerBriefs in Applied Sciences and Technology (pp. 1-9). Springer Verlag. https://doi.org/10.1007/978-3-030-19581-6_1

Ramos, R., Cantillo, V., Arellana, J., \& Sarmiento, I. (2017). From restricting the use of cars by license plate numbers to congestion charging: Analysis for Medellin, Colombia. Transport Policy, 60. https://doi.org/10.1016/j.tranpol.2017.09.012

Reyer, M., Fina, S., Siedentop, S., \& Schlicht, W. (2014). Walkability is only part of the story: Walking for transportation in Stuttgart, Germany. International Journal of Environmental Research and Public Health, 11(6), 5849-5865. https://doi.org/10.3390/ijerph110605849

Saelens, B E, Sallis, J. F., \& Frank, L. D. (2003). Environmental correlates of walking and cycling: Findings from the transportation, urban design, and planning literatures. Annals of Behavioral Medicine, 25(2), 80-91. https://doi.org/10.1207/S15324796ABM2502_03

Saelens, Brian E., \& Handy, S. L. (2008). Built environment correlates of walking: A review. In Medicine and Science in Sports and Exercise (Vol. 40, Issue 7 SUPPL.1, p. S550). NIH Public Access. https://doi.org/10.1249/MSS.0b013e31817c67a4

Sagaris, L., \& Tiznado-Aitken, I. (2020). Walking and gender equity: Insights from Santiago, Chile. In D. Oviedo, N. Villamizar-Duarte, \& A. Ardila Pinto (Eds.), Urban mobility and equity in Latin America. Emerald Books.

Sallis, J. F., Cervero, R. B., Ascher, W., Henderson, K. A., Kraft, M. K., \& Kerr, J. (2006). an Ecological Approach To Creating Active Living Communities. Annual Review of Public Health, 27(1), $297-322$. https://doi.org/10.1146/annurev.publhealth.27.021405.102100

Sallis, J. F., Frank, L. D., Saelens, B. E., \& Kraft, M. K. (2004). Active transportation and physical activity: Opportunities for collaboration on transportation and public health research. Transportation Research Part A: Policy and Practice, 38(4), 249-268. https://doi.org/10.1016/j.tra.2003.11.003

Schwanen, T., Lucas, K., Akyelken, N., Cisternas Solsona, D., Carrasco, J.-A., \& Neutens, T. (2015). Rethinking the links between social exclusion and transport disadvantage through the lens of social capital. Transportation Research Part A: Policy and Practice, 74, 123-135. https://doi.org/10.1016/j.tra.2015.02.012

Southworth, M. (2005). Designing the Walkable City. Journal of Urban Planning and Development, 131(4), 246257. https://doi.org/10.1061/(ASCE)0733-9488(2005)131:4(246)

Tian, G., \& Ewing, R. (2017). A walk trip generation model for Portland, OR. Transportation Research Part D: Transport and Environment, 52, 340-353. https://doi.org/10.1016/j.trd.2017.03.017

Timperio, A., Ball, K., Salmon, J., Roberts, R., Giles-Corti, B., Simmons, D., Baur, L. A., \& Crawford, D. (2006). Personal, family, social, and environmental correlates of active commuting to school. American Journal of Preventive Medicine, 30(1), 45-51. https://doi.org/10.1016/j.amepre.2005.08.047

Vecchio, G., Tiznado-Aitken, I., \& Hurtubia, R. (2020). Transport and equity in Latin America: a critical review of socially oriented accessibility assessments*. Transport Reviews, 40(3), 354-381. https://doi.org/10.1080/01441647.2020.1711828

Yañez-Pagans, P., Martinez, D., Mitnik, O. A., Scholl, L., \& Vazquez, A. (2018). Urban Transport Systems in Latin America and the Caribbean: Challenges and Lessons Learned. 